\title{
Conjunctival Immunocytochemistry with Interferon Gamma and Caspase 3 for Clinical Staging of Keratoconjunctivitis Sicca (KCS) in Dogs
}

\author{
Christina John', Aswathy Gopinathan ${ }^{2} *$ Kiranjeet Singh ${ }^{3}$, Chelladurai Sowbharenya ${ }^{1}$, \\ Naveen Kumar ${ }^{2}$, Monalisa Sahoo ${ }^{3}$ and Ravi Kant Agrawal ${ }^{1}$
}

${ }^{1}$ LPT Division, Council of Agricultural Research-Indian Veterinary Research Instistute, Izzatnagar, Barielly, Uttar Pradesh, India

${ }^{2}$ Division of Surgery, ${ }^{3}$ Division of Pathology LPT Division, Council of Agricultural ResearchIndian Veterinary Research Instistute, Izzatnagar, Barielly, Uttar Pradesh, India

*Corresponding author

\section{A B S T R A C T}

Keywords

Caspase -3, Dogs, Immuno cytochemistry, Interferon- gamma, Keratoconjunctivitis sicca

Article Info

Accepted:

24 September 2020 Available Online: 10 October 2020
The study was conducted on 67 client-owned dogs affected with Keratoconjunctivitis Sicca (KCS) to evaluate the expression of Caspase-3 and Interferon gamma in conjunctival cells. After complete ophthalmic examinations cases were staged into Early (E), Late (L) and ulcer group (R). Conjunctival scrapings for immunocytochemical expression of Caspase-3 and INF gamma and tissue samples for histopathological confirmation of KCS were collected from early KCS, late KCS and apparently healthy animals. The prevalence of KCS cases was found to be $3.33 \%$ (67/1997) in dogs. Corneal ulcers (R) due to KCS constituted $38 \%$ (27), early KCS 36\% (24) and late KCS 24\% (16) among cases. Cases with early and late stages of KCS were having significantly $(0.05 \%)$ high expression for Caspase 3 and INF gamma as compared to apparently healthy animals. In Group E, $89.33 \%$ and $85.04 \%$ of cells were found positive for Caspase -3 and interferon gamma, respectively. In group L $25.57 \%$ and $85.05 \%$ of cells were found positive for Caspase -3 and interferon gamma, respectively. Immunocytochemical findings of present study corroborated $\mathrm{T}$ cell proliferation and apoptosis as major pathological events at different stages of KCS.

\section{Introduction}

Keratoconjunctivitis Sicca (KCS) which is also known as dry eye is an inflammatory condition of the ocular surface caused by pathologic reduction in the aqueous component of the tear film (Williams, 2008). Deficiency in the aqueous component of tear film might predispose the ocular surface to infection (Davidson and Kuonen, 2004).
Breeds like Chinese pugs, Bull dogs, Lhasa Apso, Terriers, Shih Tzu and Pekingese were usually affected (Whitley et al., 1991). Several systemic diseases, either endocrine or infectious, are associated with the development of KCS (Culllen et al., 2005; Sanchez et al., 2007). One of the widely accepted causes is a local immune mediated disease affecting the lacrimal glands (Sanchez et al., 2007; Dodi, 2015). Immunological 
similarities have been observed between dogs and humans with idiopathic KCS. Abnormality in lacrimal gland function can result in an unstable and unrefreshed tear film having altered composition like elevated tear osmolarity, presence of pro-inflammatory mediators and proteases, which no longer supports the normal functioning of the ocular surface (Bhavsar et al., 2011).

The immunologically activated epithelial cells can be targeted by lymphocytes in cytotoxic reactions and/or that they participate in the recruitment of inflammatory cells (Wakamatsu et al., 2008). Release of inflammatory cytokines by infiltrating inflammatory cells and diseased lacrimal epithelial cells themselves further causes epithelial cell dysfunction or apoptosis (Zhu et al., 2002).

It is still unclear whether oxidative stress is the primary initiating event that is associated with dry eye disease in dogs. The role of inflammatory cytokines and matrix metalloproteinases (MMPs) in the pathogenesis of dry eye seems to be very important for understanding KCS and for the discovery of new therapeutic agents (Djalilian et al., 2005; Gumus and Cavanagh, 2009). The present study was conducted for clinical characterization of different stages of KCS and to evaluate the expression of Caspase-3 and Interferon gamma in early and late stages of KCS in canine.

\section{Materials and Methods}

The study was carried out in dogs with ocular diseases presented to the outpatient unit of Referral Veterinary Polyclinic cum Teaching Veterinary Clinical Complex, IVRI. All the animals were screened for KCS with Schirmer Tear Test (STT) and clinical evaluation. Those animals with mild and moderate STT reading $(>5 \mathrm{~mm} / \mathrm{min})$ were randomly placed in group E (early). Those with severe STT score $(<5 \mathrm{~mm} / \mathrm{min})$, along with mucoid discharge were randomly placed in group L (late). Dogs with corneal ulcer due to KCS were placed in group R (reflex).

Sixty seven clients owned dogs with different stages of KCS were selected for the study. Breeds like Chinese pugs, Pomeranian, GSD (German shepherd) and Mastiff were included. Detailed history was recorded and complete ophthalmic examination was carried out in all the cases. Menace reflex, palpebral reflex, pupilary light reflex, conjunctival hyperaemia, ocular discharge, corneal clarity, corneal ulcer, corneal vessel length, corneal vessel density, corneal pigmentation area, corneal pigmentation density, STT, FDT (Fluorescent Dye Test) and RBDT (Rose Bengal Dye Test) were performed. Consent for collection of samples was taken from all owners.

Physiological parameters like heart rate, respiratory rate and rectal temperature were recorded in all the cases. Blood samples were collected and parameters like Haemoglobin, Packed cell volume, Total Leukocyte Count, Total Erythrocyte Count, Differential Leukocyte count and blood glucose were performed using standard procedures. Serum was separated and subjected to $\mathrm{T}_{4}, \mathrm{~T}_{3}, \mathrm{TSH}$ and Cortisol estimation using commercially available ELISA kits. Blood smears were also prepared for parasitological examinations using standard procedures. Animals having KCS due to endocrinopathies were excluded from the study since they may have a different pathophysiology of KCS.

Ophthalmological evaluation was carried out by same ophthalmologist with visual examination and photographic evaluation using subjective scoring for different parameters. 
Tear production was measured by means of STT commercial strips (Schirmer Tear Test, ophthalmic strips, Tarun enterprises, Allahabad-India). The strips were placed in the ventral conjunctival fornix within onethird distance from the lateral canthus. After one minute, STT was read and values were recorded. The schirmer tear test values were interpreted and were scored in the increasing order of severity. 1: Normal: $>/=15 \mathrm{~mm} / \mathrm{min}$ 2: Mild or subclinical KCS: $11-14 \mathrm{~mm} / \mathrm{min} 3$ : Moderate to mild KCS: 6-10 $\mathrm{mm} / \mathrm{min}$ 4: Severe KCS: </= $5 \mathrm{~mm} / \mathrm{min}$ (Corr, 2015).

Conjunctival scrapings for immunocytochemical evaluation and tissue samples for histopathological studies were collected after instillation of proparacain hydrochloride (Paracain 0.5\%, Sunway Pvt. Ltd- Mumbai, India) solution from early $\mathrm{KCS}$, late KCS and apparently healthy animals. The blunt end of a sterile scalpel blade was used to scrape a required amount of cells. The cells from the conjunctiva were rolled on poly-L-lysine-coated slides (Sigma, St Louis, MO, USA) and incubated with $100 \%$ methanol (kept at $-20{ }^{0} \mathrm{C}$ ) for $10 \mathrm{~min}$. Then the slides were washed with PBS for 10 mins. After this, permeabilization was done with PBS containing $0.1-0.25 \%$ Triton X-100 for 10 mins. The cells were washed three times in phosphate-buffered saline (PBS, 0.05 $\mathrm{M}, \mathrm{pH}$ 7.6) for $5 \mathrm{~min}$ each wash followed by incubation in a humidified chamber with 1:10 normal goat serum in PBS at $37^{\circ} \mathrm{C}$ for $1 \mathrm{~h}$ to block non-specific sites. The blocking serum was drained and replaced with either primary antibody (rabbit anti-caspase- 3 hyperimmune serum; 1:100; rabbit anti- Gamma interferon hyperimmune serum, 1:50, optimal working dilution) or non-immune goat serum as a control and incubated overnight at $4{ }^{\circ} \mathrm{C}$. The cells were thoroughly washed in PBS three times to remove unbound antibody. Goat antirabbit IgG horseradish peroxidase conjugate (1:200 dilutions, Sigma-Aldrich, USA) was incubated with the sections at $37^{\circ} \mathrm{C}$ for $1 \mathrm{~h}$. Three washes were performed in PBS, and sections were immersed in a freshly prepared solution of 3-3'-diaminobenzidine tetrahydrochloride (DAB) and $\mathrm{H}_{2} \mathrm{O}_{2}$ /urea tablets (Sigma) in distilled water. Sections were incubated at $37^{\circ} \mathrm{C}$ for 1 min or until the sections turned light brown in color. The slides were washed in running tap water to stop the reaction and counterstained with Mayer's hematoxylin for $1 \mathrm{~min}$. The sections were dehydrated, cleared, and mounted. For each batch of staining, test sections were also incubated with $10 \%$ solution of normal goat serum in PBS as a negative control. For immunocytochemical evaluation of Caspase 3 and INF gamma expression, 200 cells were counted from each sample. Average percentage of cells was counted and was used for evaluation and grading. The immunocytochemical expression of Caspase 3 and INF gamma were only compared amongst the samples collected from early KCS, late KCS and apparently healthy patients. Tissue samples were washed thoroughly in normal saline and fixed in $1 \%$ buffered formalin for $48 \mathrm{~h}$ and processed in routine manner for Haematoxylin and Eosin staining. The stained sections were examined for the histopathological changes.

The results were presented as the mean $\pm \mathrm{SE}$. The statistical analysis was done using student " $t$ " test and one-way ANOVA for parametric variables. Kruskal-Wallis test was used to compare the non parametric variable (Snedecor and Cochran, 1989). Wilcoxon signed rank test was used to evaluate non parametric data within intervals (Wardlaw, 1985). Statistical analysis was performed using SPSS (IBM) software.

\section{Results and Discussion}

Ocular diseases were recorded in 119 cases among a total of 1997 canine cases presented 
to our clinic from August 2016 to May 2017. A total 67 out of 119 canine cases were found affected with different stages of KCS. Prevalence of KCS in dogs in our study was found to be $3.33 \%$ (67/1997). Corneal ulcers (R) due to KCS constituted $38 \%$ (27 cases), early KCS $36 \%$ (24 cases) and late KCS $24 \%$ (16 cases). Pug breed was found mostly affected with KCS (55/67).

Physiological and haemato-biochemical parameters did not show any significant variation between the groups except for eosinophil count which was significantly high in group E. The degree of pigmentation area and pigmentation density did not vary among the groups. STT values varied significantly among all the groups (Table 1 and Fig. 1).

FDT scores were also significantly high in group R (Fig. 2), whereas RBD score (Fig. 3) was significantly low in group $\mathrm{E}$ (Table 1$)$.

Groups E and L were having significantly high expression for Caspase 3 and INF gamma as compare to healthy animals (Fig. 4, 5,6 , and 7). The average percentage of cells in early and late samples is shown in table 2 . Histopathology of conjunctival samples showed conjunctival hyperemia along with increased infiltration of lymphocytes (Fig. 8).

In Group E, $89.33 \%$ and $85.04 \%$ of cells were found positive for Caspase -3 and Interferon gamma, respectively. In group L, $25.57 \%$ and $85.05 \%$ of cells were found positive for Caspase-3 and Interferon gamma, respectively (Table 2). It was also found that group $\mathrm{E}$ was having a significantly $(\mathrm{P}<0.05)$ high number of apoptotic cells when compared to group L. Also group $\mathrm{E}$ and $\mathrm{L}$ had a significantly low number of normal cells, $10.62 \%$ and $74.43 \%$, respectively, when compared with the normal conjunctival scrapping which had $91.35 \%$ normal cells (Table 2).
Keratoconjunctivitis Sicca (KCS) is a common canine ophthalmic disease resulting from deficiency in the pre-corneal tear film. Though there are several known causes of $\mathrm{KCS}$ in dogs, an underlying etiology is not clearly discernible (Berdoulay et al., 2005). Many histopathological studies suggest KCS development as the result of immunemediated inflammation and destruction of the lacrimal glands (Williams, 2008).

Our study has approached to characterize early, late and ulcerative form of $\mathrm{KCS}$ through subjective evaluation scores and immunocytochemistry of conjunctival samples. KCS is a common and probably undiagnosed / underdiagnosed condition in the general canine population (Williams, 2008). Its prevalence has been reported to be low $0.4 \%, 4 \%$ and high $35 \%(17,20)$. The prevalence of $\mathrm{KCS}$ as observed to be $3.33 \%$ in our study. STT is an important criterion to judge tear production, with readings less than $10 \mathrm{~mm} / \mathrm{min}$ been indicative of dry eye (Williams, 2008). It was also observed that the normal tear production in breeds predisposed to $\mathrm{KSC}$ is lower compared to other breeds. Pugs were found mostly affected with KCS (55/67). Classification of KCS as early, late and ulcer group is a first attempt as per our knowledge. Though KCS is largely neglected, ulcerative form of KCS receives attention of owners and hence its clinical presentation is more often compared to early and late form of KCS.

In a normal corneal tissue, the free radicals produced in response to stress are being scavenged by the anti oxidant defense of the cornea. In dry eye syndrome, overwhelming nature of oxidative stress leads to the failure of tear antioxidant defenses as evidenced by the depletion of antioxidant enzymes such as superoxide dismutase, catalase, and glutathione peroxidase. This can lead to chronic inflammation and pigmentation 
(Saccà et al., 2013). It has been reported that in advanced cases the entire cornea may be thickened, and pigmented (Slatter, 1973). Late stage of KCS has pronounced squamous metaplasia of epithelial cells and fibrous tissue proliferation (Kaswan et al., 1984). This could be a reason for the decreased corneal vascularization visible in the late group.

Since the aqueous deficit is more in Late KCS, STT values were considerably lower. Reflex tear enhances the STT values in ulcerative KCS (Berger et al., 1998). Tear deficits in later stages of KCS has been postulated because of $\mathrm{T}$ cell mediated cytotoxicity of the lacrimal gland, apoptosis associated damage of glandular epithelial cells or cytokines mediated damage to the neurologic stimulus of tear production (Williams, 2008). Most of the animals in the Early and Late KCS did not retain fluorescein dye since the epithelial loss was not evident and positive fluorescein staining was absent. In roughened corneal surface there is slight retention of dye (fluorescein stippling) (Lewin, 2014).

Table.1 Values of mean \pm SE of score for different ocular parameters

\begin{tabular}{|l|c|c|c|}
\hline \multicolumn{1}{|c|}{ Parameter } & Early & Late & Reflex \\
\hline Menace Reflex & $1.81 \pm 0.09^{\mathrm{a}}$ & $0.71 \pm 0.2^{\mathrm{b}}$ & $0.13 \pm 0.09^{\mathrm{b}}$ \\
\hline Palpebral Reflex & $1.91 \pm 0.07$ & $1.67 \pm 0.11$ & $1.88 \pm 0.09$ \\
\hline Corneal Clarity & $1.38 \pm 0.18^{\mathrm{a}}$ & $2.33 \pm 0.27^{\mathrm{b}}$ & $3.38 \pm 0.19^{\mathrm{c}}$ \\
\hline Ocular Discharge & $1.14 \pm 0.1^{\mathrm{a}}$ & $1.71 \pm 0.1^{\mathrm{b}}$ & $1.63 \pm 0.13^{\mathrm{b}}$ \\
\hline Conjunctival Hyperemia & $0.81 \pm 0.19$ & $1.05 \pm 0.16$ & $1.06 \pm 0.11$ \\
\hline Corneal Ulcer & $0.14 \pm 0.08^{\mathrm{a}}$ & $0.57 \pm 0.16^{\mathrm{a}}$ & $2.56 \pm 0.16^{\mathrm{b}}$ \\
\hline Corneal Vessel Length & $0.14 \pm 0.1^{\mathrm{a}}$ & $0.38 \pm 0.16^{\mathrm{ab}}$ & $0.94 \pm 0.23^{\mathrm{b}}$ \\
\hline Corneal Vessel Density & $0.14 \pm 0.1^{\mathrm{a}}$ & $0.38 \pm 0.15^{\mathrm{a}}$ & $1.31 \pm 0.27^{\mathrm{b}}$ \\
\hline Corneal Pigmentation Area & $1.14 \pm 0.24$ & $2.33 \pm 0.38$ & $1.25 \pm 0.27$ \\
\hline Corneal Pigmentation Density & $1.33 \pm 0.25$ & $1.81 \pm 0.27$ & $1.81 \pm 0.28$ \\
\hline STT & $2.43 \pm 0.11^{\mathrm{a}}$ & $4 \pm 0^{\mathrm{b}}$ & $1.38 \pm 0.18^{\mathrm{c}}$ \\
\hline FDT & $0.14 \pm 0.14^{\mathrm{a}}$ & $0.29 \pm 0.1^{\mathrm{a}}$ & $1 \pm 0^{\mathrm{b}}$ \\
\hline RBD & $3.14 \pm 0.31^{\mathrm{a}}$ & $4.48 \pm 0.21^{\mathrm{b}}$ & $4.5 \pm 0.22^{\mathrm{b}}$ \\
\hline
\end{tabular}

Values with different alphabets differ significantly $(\mathrm{P}<0.05)$ between groups

Table.2 Percentage of cells showing immunoreactivity to caspase and interferon gamma

\begin{tabular}{|c|c|c|c|}
\hline Groups & E & L & Healthy Animals \\
\hline Caspase Positive & $89.34^{\mathrm{a}}$ & $25.56^{\mathrm{b}}$ & $8.64^{\mathrm{c}}$ \\
\hline Caspase Negative & $10.66^{\mathrm{a}}$ & $74.43^{\mathrm{b}}$ & $91.35^{\mathrm{c}}$ \\
\hline INF $\boldsymbol{\gamma}$ Positive & $85.04^{\mathrm{a}}$ & $85.04^{\mathrm{a}}$ & $7.67^{\mathrm{b}}$ \\
\hline INF $\boldsymbol{\gamma}$ Negative & $14.95^{\mathrm{a}}$ & $21.60^{\mathrm{a}}$ & $92.32^{\mathrm{b}}$ \\
\hline
\end{tabular}

Values with different alphabets differ significantly $(\mathrm{P}<0.05)$ between groups 
Fig.1 Mean \pm SE values of score for schirmer tear test in different groups

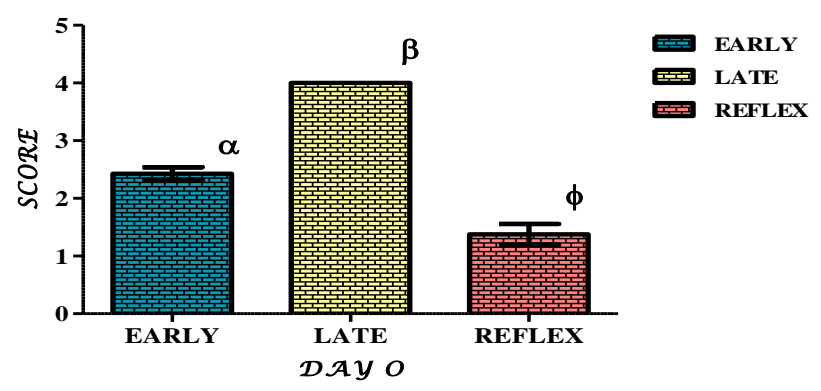

Columns with different alphabets differ significantly $(\mathrm{P}<0.05)$ between groups

Fig.2 Mean \pm SE values of score for fluorescein dye test in different groups

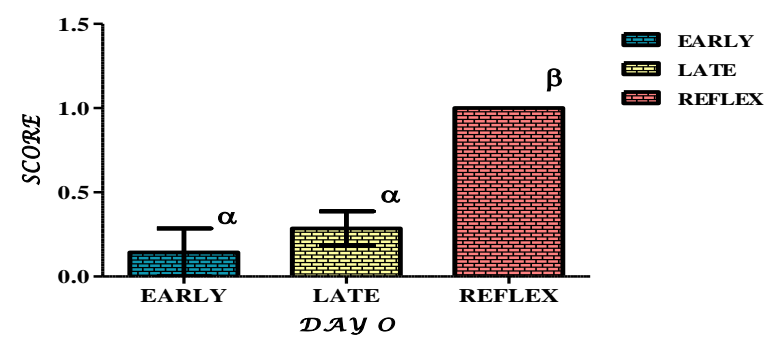

Columns with different alphabets differ significantly $(\mathrm{P}<0.05)$ between groups

Fig.3 Mean \pm SE values of score for RBD test in different groups on Day 0

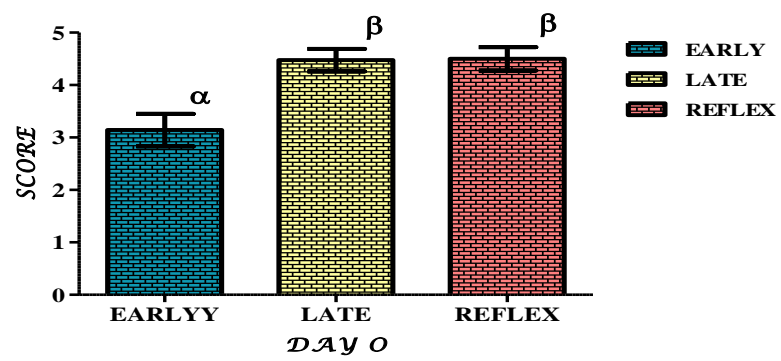

Columns with different alphabets differ significantly $(\mathrm{P}<0.05)$ between groups

Fig.4 Average cells (\%) expressing INF- gamma in groups E, L and apparently healthy animals

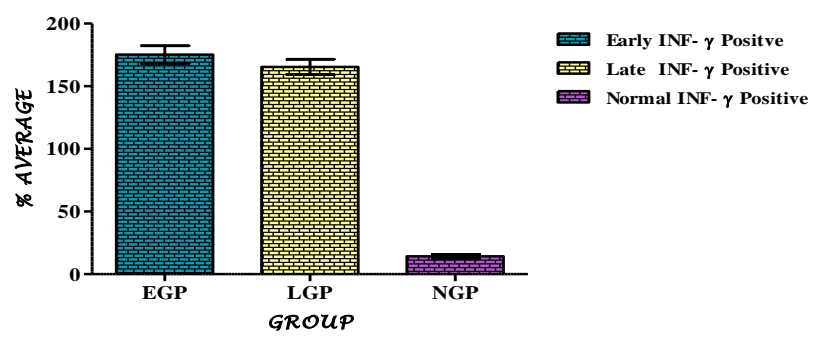

Columns with different alphabets differ significantly $(\mathrm{P}<0.05)$ between groups 
Fig.5 Average cells (\%) expressing of caspase 3 in groups E, L and apparently healthy animals

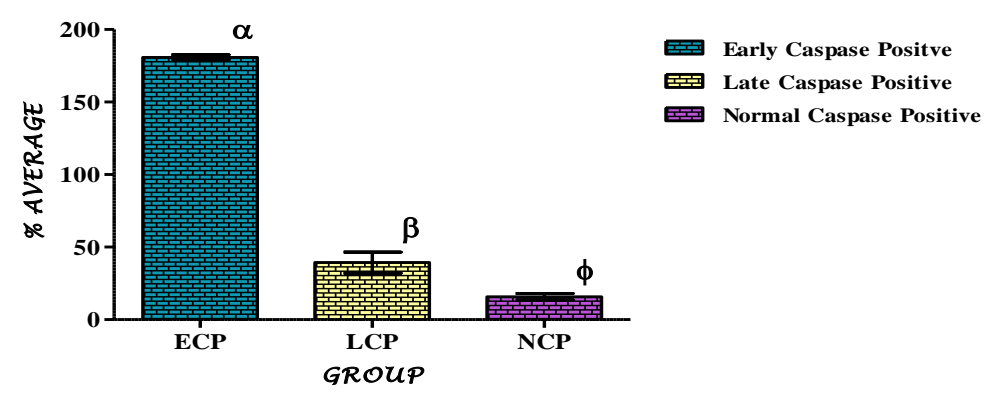

Columns with different alphabets differ significantly $(\mathrm{P}<0.05)$ between groups

Fig.6 Immunocytochemistry changes in normal (A), in early (B) and late KCS (C) conjunctiva scrapings with interferon gamma

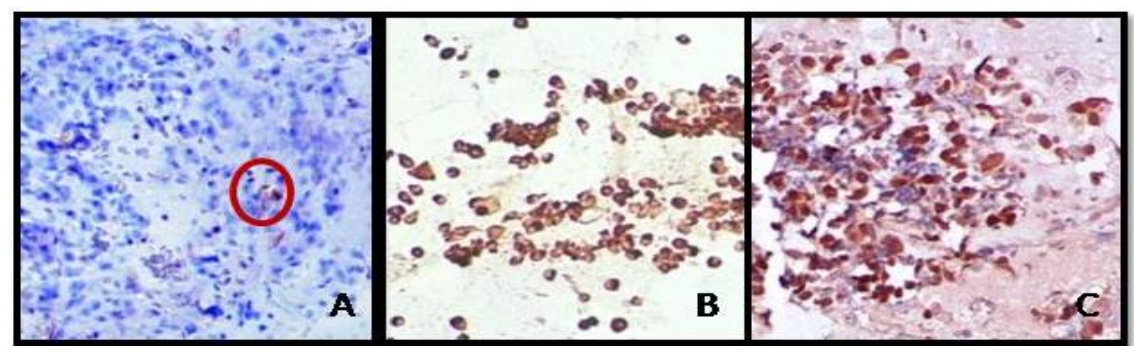

Fig.7 Immunocytochemistry changes in normal (A), in early (B) and late KCS (C) conjunctiva scrapings with CASPASE-3

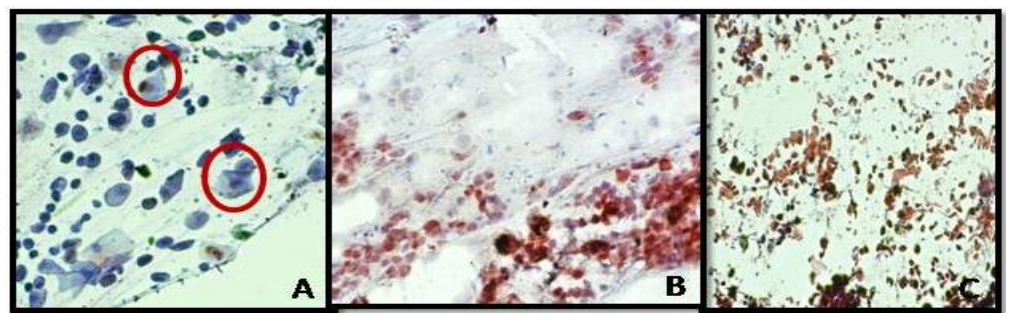

Fig.8 Histopathology of conjunctival samples showed conjunctival hyperemia along with increased infiltration of lymphocytes in normal, early KCS and late KCS cases

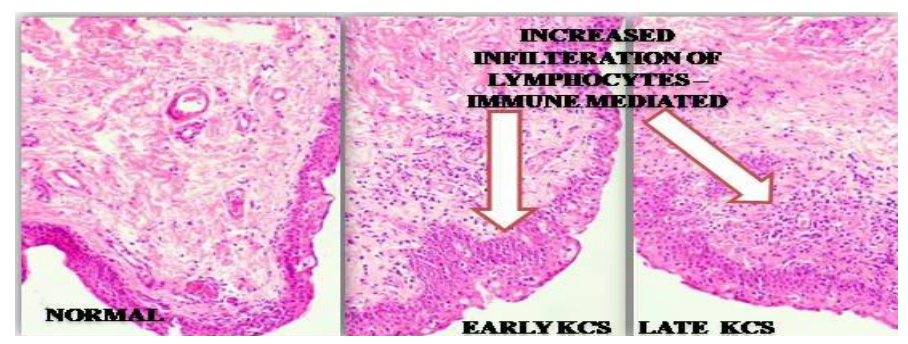


Animals showed varying degrees of stain retention with maximal retention in group $\mathrm{R}$ when compared to groups $\mathrm{L}$ and $\mathrm{E}$. Fluorescein stippling was recorded in few cases of late KCS of present study. This variation in retention of stain could be due to increased epithelial loss in Reflex group and more mucin unprotected areas in animals of group L. since the tear film quality was affected at this stage itself, a slight degree of dye retention in Early group was showed. RBD is mainly used for diagnosing KCS and it is supposed to be more sensitive than the STT for evaluating KCS (Gelatt, 1972).

Apoptosis and $\mathrm{T}$ - cell proliferation are the major causes of KCS. INF $\gamma$ is identified as a modulator of increased apoptosis and Caspase 3 as an activator of apoptotic damage in the conjunctival epithelium (Wolf and Green 1999; Zhang et al., 2011). Interferon- $\gamma$ is secreted by Th1 lymphocytes, CD8 cytotoxic lymphocytes, natural killer (NK) cells, and natural killer T (NKT) cells. It is critical for innate and adaptive immune responses, including defense against certain bacterial and viral infections. Elevated IFN- $\gamma$ expression has been identified in a number of autoimmune diseases, including systemic lupus erythematosis, Sjögren syndrome, inflammatory bowel disease, and multiple sclerosis. Exposure of the mouse ocular surface to desiccating stress increased IFN- $\gamma$ production in the conjunctiva by $\mathrm{NK}$ and Th1 cells (Pflugfelder et al., 2015). Hence this study evaluated the expression of Caspase 3 and INF gamma at early and late stages of KCS. Normally when there is no inflammation, these $\mathrm{T}$ lymphocytes undergo apoptosis. But in the presence of inflammation, as in KCS, T cells may get activated, become resistant to apoptosis and secrete pro-inflammatory cytokines which results in even more $\mathrm{T}$ cell activation (Dana and Hamrah, 2002; Hamarah et al., 2004). Interferon $\gamma$ is identified as a modulator of increased apoptosis in the conjunctival epithelium (Zhang et al., 2011) which could be the probable reasons for increased INF $\gamma$ expression in early and late stages of KCS. It is known to induce HLA- DR expression and apoptosis in conjunctival cells (Mircheff et al., 1994).

Increased production of IFN- $\gamma$ promotes development of conjunctival squamous metaplasia and loss of goblet cells. Greater MMP activity on the ocular surface increases the risk of developing keratolysis and sightthreatening corneal ulceration (Triantafyllopoulou and Moutsopoulos, 2007; Chotikavanich, et al., 2009). Excessive levels of oxidative stress induced reactive oxygen species will induce apoptosis by inducing DNA damage (Stennicke et al., 1998). Studies have also demonstrated that Caspase- 3 was also highly positive in conjunctiva of dry eye disease models (Baudouin et al., 2013). It has been suggested that Caspase -3 is the primary activator of apoptotic DNA fragmentation (Wolf and Green, 1999). The proinflammatory property of tear hyperosmolarity can activate apoptosis (Baudouin et al., 2013). Experimental dry eye studies have shown that apoptosis was associated with conjunctival goblet cell loss (Contreras-ruiz et al., 2013).

Pathogenic processes such as apoptosis, also sustained by metabolic changes, may induce and maintain the ocular surface damage characteristic of dry eye. However, more severe oxidative stress can exhaust the mediators of apoptosis (Valko et al., 2005). This may be the reason for decreased number of Caspase-3 positive cells in group L compared to group $\mathrm{E}$.

In conclusions the immunocytochemical expression of Caspase- 3 and INF gamma in conjunctival cells clearly depict KCS as a primary immune mediated disease and 
differential expression of these will help in the clinical staging of KCS in dogs. Conjunctival histology with lymphocyte proliferation also corroborates these findings. Subjective clinical scores can be helpful in staging KCS into early and late stages along with STT and RBD tests. Therapeutic clues can be drawn from clinical staging of KCS and immunocytochemical analysis. Anti apoptosis based strategies can help in early stages of KCS while exhaustion of apoptotic markers in late stages can be addressed to maintain clarity and structural integrity of cornea.

\section{Acknowledgements}

The author acknowledge the scholars, scientific and technical staff of Division of Surgery and Teaching Veterinary Clinical Complex cum Referral Veterinary Polyclinic, DBT (Financial help) and Director ICARIndian Veterinary Research Institute, Izzatnagar, Bareilly, Uttar Pradesh, India for providing necessary support and help at various level for the study

\section{References}

Baudouin C, Aragona P, Messmer EM, Tomlinson A, Calonge M, Boboridis KG, Akova YA, Geerling G, Labetoulle M, Rolando. Role of hyperosmolarity in the pathogenesis and management of dry eye disease: proceedings of the OCEAN group meeting. Ocul Surf 2013; 11: 246-258.

Berdoulay A, English RV, Nadelstein B. Effect of topical $0.02 \%$ tacrolimus aqueous suspension on tear production in dogs with keratoconjunctivitis sicca. Vet Ophthalmol 2005; 8: 225-232.

Berger SL, King VL. The fluctuation of tear production in the dog. J Amer Anim Hospi Aassoc 1998; 34: 79-83.

Bhavsar AS, Bhavsar SR, Jain SM. A review on recent advances in dry eye: Pathogenesis and management. Oman $J$ Ophthalmol 2011; 4: 50-56.
Chotikavanich, S, De Paiva CS, Li De Q, Chen JJ, Bian F, Farley WJ, Pflugfelder SC. Production and activity of matrix metalloproteinase-9 on the ocular surface increase in dysfunctional tear syndrome. Invest Ophthalmol Vis Sci 2009; 50: 32033209.

Contreras-ruiz L, Ghosh-mitra A, Shatos MA, Dartt DA, Masli S. Modulation of conjunctival goblet cell function by inflammatory cytokines. Mediat Inflamm 2013; 636812, 1-11. doi.org/10.1155/2013/

Corr A. Canine Keratoconjunctivitis Sicca (KCS). Canine dry eye metropolitan veterinary associates \& emergency services. 2015; newsletter. 4.

Cullen CL, Ihle SL, Webb AA, Mccarville C. Keratoconjunctival effects of diabetes mellitus in dogs. Vet Ophthalmol 2005; 8: 215-224.

Dana MR, Hamrah P. Role of immunity and inflammation in corneal and ocular surface disease associated with dry eye. $A d v$ in Exper Medi and Biol 2002; 506: 729-738.

Davidson HJ, Kuonen VJ. The tear film and ocular mucins. Vet Ophthalmol 2004; 7: 7177.

Djalilian AR, Pedram H, Pflugfelder SC. Cornea. In: Krachmer, Mannis, Holland, editors. 2005: 2nd ed. Vol. 1. Philadeiphia: Elsevier, pp. 521-538.

Dodi PL. Immune-mediated keratoconjunctivitis sicca in dogs: current perspectives on management. Vet Medi Res and Rep 2015; 6: 341-347.

Gelatt KN. Vital staining of the canine cornea and conjunctiva with rose bengal. J Amer Anim Hosp Assoc 1972; 8: 17-22.

Gumus K, Cavanagh DH. The role of inflammation and antiinflammation therapies in keratoconjunctivitis sicca. Clin Ophthalmol 2009; 3: 57-67.

Hamarah P, Haq SO, Gulati A, Dana MR. Mechanism of ocular surface immune response. In: Pflugflelder SC, Roger W.B, editors. Dry eye and Ocular Surface disorders. New York: Marcel Dekker; 2004: pp. 111-141.

Kaswan RL, Martin CL, Chapman (Jr.) WL. Keratoconjunctivitis sicca: histopathologic study of nictitating membrane and lacrimal 
glands from 28 dogs. Am J Vet Res 1984; 45: $112-118$.

Lewin A. Keratoconjunctivitis sicca in dogs: causes, diagnosis and treatment. Vet Times 2014:, The website for the veterinary profession. http://www.vettimes.co.uk

Mircheff AK, Gierow JP, Wood RL. Traffic of major histocompatibility complex class II molecules in rabbit lacrimal gland acinar cells. Invest Ophthalmo Vis Sci 1994; 35: 3943-3951.

Pflugfelder SC, De paiva CS, Moore QL, Volpe EA, De-quan LI, Gumus K, Zaheer ML, Corrales RM. Aqueous Tear Deficiency Increases Conjunctival Interferon- $\gamma$ (IFN- $\gamma)$ Expression and Goblet Cell Loss. Invest Ophthalmol Vis Sci 2015; 56: 75457550.

Saccà SC, Roszkowska AM, Izzotti A. Environmental light and endogenous antioxidants as the main determinants of non-cancer ocular diseases. Mutat Res Rev Mutat Res 2013; 752: 153-171.

Sanchez RF, Innocent G, Mould J, Billson FM. Canine keratoconjunctivitis sicca: disease trends in a review of 229 cases. JSAP 2007; 48: 211-217.

Slatter DH. Keratoconjunctivitis sicca in the dog produced by oral phenazopyridine hydrochloride. JSAP 1973; 14: 749-772.

Snedecor GW, Cochran WG. The binomial distribution. Statistical Methods. Iowa State University Press, Ames. 1989: Pp. 117-120.

Stennicke HR, Jürgensmeier JM, Shin H, Deveraux Q, Wolf BB, Yang X, Zhou Q, Ellerby HM, Ellerby LM, Bredesen D, Green DR, Reed JC, Froelich CJ, Salvesen GS. Pro-caspase-3 is a major physiologic target of caspase-8. J Biol Chem 1998; 27: 2784-2790.
Triantafyllopoulou A, Moutsopoulos H. Persistent viral infection in primary Sjogren's syndrome: review and perspectives. Clin Rev Allergy Immunol 2007; 32: 210-214.

Valko, MM, Morris H, Cronin MT. Metals, toxicity and oxidative stress. Curr Medi Chem 2005; 12: 1161-1208.

Wakamatsu TH, Dogru M, Tsubota K. Tearful relations: oxidative stress, inflammation and eye diseases. Arq Bras Oftalmol 2008; 71: 72-79.

Wardlaw AC. Practical Statistics for Experimental Biologists. John Wiley \& Sons, ChichesterNew York-Brisbane-Toronto-Singapore 1985. IX, 290 S.,

Whitley RD, Mclaughlin SA, Gilger BC, Lindley DM. The treatment for keratoconjunctivitis sicca. Vet Medi 1991; 86: 1076-1093.

Williams DL. Immunopathogenesis of keratoconjunctivitis sicca in the dog. Vet Clin North Am Small Anim Pract 2008; 38: 251-268.

Wolf BB, Green DR. Suicidal tendencies: apoptotic cell death by caspase family proteinases. J Biol Chem 1999; 274: 2004920052.

Zhang X, Chen W, De paiva CS, Corrales RM, Volpe EA, Mcclellan AJ, Farley WJ, Li DQ, Pflugfelder SC. Interferon- $\gamma$ exacerbates dry eye-induced apoptosis in conjunctiva through dual apoptotic pathways. Invest Ophthalmol Vis Sci 2011; 52: 6279-6285.

Zhu Z, Stevenson D, Ritter T, Schechter JE, Mircheff AK, Kaslow HR, Trousdale MD. Expression of IL-10 and TNF-inhibitor genes in lacrimal gland epithelial cells suppresses their ability to activate lymphocytes. Cornea 2002; 21: 210-214.

\section{How to cite this article:}

Christina John, Aswathy Gopinathan, Kiranjeet Singh, Chelladurai Sowbharenya, Naveen Kumar, Monalisa Sahoo and Ravi Kant Agrawal. 2020. Conjunctival Immunocytochemistry with Interferon Gamma and Caspase 3 for Clinical Staging of Keratoconjunctivitis Sicca (KCS) in Dogs. Int.J.Curr.Microbiol.App.Sci. 9(10): 2952-2961.

doi: https://doi.org/10.20546/ijcmas.2020.910.356 